\title{
Influência da radiação de luz sobre acervos museológicos
}

\author{
Norma Ciaflone Cassares \\ Library Services \\ Yara Lígia Mello Moreira Petrella \\ Museu Paulista da USP
}

Uma das causas mais comuns de degradação de materiais de acervos museológicos, bibliográficos e arquivísticos é a ação das radiações de luz, tanto natural quanto artificial presentes nos ambientes das instituições. Essa iluminação, natural e artificial, é um dos relevantes objetivos de estudos da área da Conservação Preventiva. As pesquisas buscam de forma incessante a compreensão da natureza da luz, os mecanismos de seu comportamento e seus efeitos sobre os diversos materiais que constituem as obras dos acervos.

Alguns indícios de degradação causada pela radiação de luz são identificados visualmente com certa facilidade, como é o caso do desbotamento ou mudança de cor dos materiais. Porém este sintoma é apenas uma indicação superficial de deterioração. Na realidade, ela atinge a estrutura química e física da matéria, e apesar de sua ação ser silenciosa, as conseqüências são desastrosas na conservação das obras.

Ó caso do desbotamento causado pela ação da luz sobre o material colorido das obras é considerado um dos fatores dos mais graves de degradação em acervos, porque desfigura a obra, altera a sua leitura de forma irreversível.

Por ser uma ação que se desenvolve fora do alcance das nossas vistas até que o dano seja detectado, é muito importante que se alcance o conhecimento amplo da natureza e comportamento dessas radiações para adotarmos procedimentos de conservação preventiva na proteção do acervo. Algumas características da radiação da luz que nos obrigam a não menosprezar seus poderes de degradação estão no fato de sua ação ser cumulativa e seus danos irreversíveis. 
Para abordamos este tema, sobre a natureza da luz e como ela age sobre os materiais expostos a ela, precisaremos da Óptica para as informações básicas e indispensáveis à compreensão de seu mecanismo, destinadas aos especialistas em conservação/ restauração.

Se fôssemos definir a luz diríamos que ela é uma forma de energia eletromagnética chamada radiação, e que tem origem a partir de uma fonte energética, tal como a luz natural e a luz artificial oriunda de lâmpadas. Chamamos de radiação ao processo de propagação de calor no qual a energia, denominada radiante, apresenta-se sob forma de ondas eletromagnéticas. A radiação é o único processo de propagação de calor que ocorre no vácuo.

A concepção moderna aceita a natureza da radiação da luz de duplo caráter: caráter de onda e de partícula devido a seu comportamento diferente conforme as condições do fenômeno que experimenta. Por exemplo: essa energia, quando atinge a matéria, pode se comportar de diferentes maneiras: pode ser refletida, absorvida, refratada, transmitida ou dispersada, dependendo das cores dos ambientes ou objetos nos quais incide. $\bigcirc$ ramo da Física que estuda estes fenômenos é a Óptica. Sabemos que as cores escuras absorvem mais a energia emitida, e as cores claras têm a propriedade de refletir.

Esse comportamento é resultado da transformação que as radiações sofrem, uma vez que energia não se perde mas se transforma. Esta transformação pode ser, por exemplo, em calor, cor, som, etc. A Teoria Quântica explica o fenômeno da emissão e absorção de energia radiante entre a fonte de origem da radiação e a matéria. A Teoria Ondulatória explica o meio de transferência da energia de um lugar a outro (da fonte de energia para a matéria), isto é, seu movimento de propagação, que acontece através de movimentos ondulatórios, portanto comportando-se como uma onda.

Para simplificar, vamos considerar que a luz se propague como conseqüência de uma vibração de partículas (fótons). Nem todos os fótons têm a mesma capacidade de causar danos, uma vez que a energia está relacionada com a freqüência da radiação. As ondas eletromagnéticas têm características que ajudam a entender as radiações eletromagnéticas, objeto deste estudo. As mais importantes dizem respeito à freqüência e comprimento de onda Comprimento de Onda é a distância entre uma partícula em uma onda e a partícula correspondente na onda seguinte, ou a distância entre duas cristas, e é de vital importância para entendermos cada tipo de onda. As variações de comprimento de ondas entre as radiações eletromagnéticas são grandes. Há radiações com comprimento de onda de milionésimos de metro e de vários quilômetros.

Já a Freqüência diz respeito ao número de vibrações ou ciclos por unidade de tempo, que também é uma característica de diferencial das ondas. A medida é dada por ciclo/segundo (FIGURA 1). Enormes faixas de freqüência de radiações compõem o espectro eletromagnético. Este espectro é representado graficamente pelos diferentes comprimentos de ondas originados por uma fonte de emissão e pode ser dividido em oito regiões principais, dependendo do caráter geral das radiações: ondas elétricas, ondas de rádio, infravermelho, luz visível, ultravioleta, raio $x$, raios gama, raios cósmicos secundários. Esses nomes indicam áreas do espectro divididas com fins didáticos e práticos, pois o espectro é contínuo e não há diferenças abruptas entre as formas de radiação: todas constituem basicamente o mesmo fenômeno físico. Referindo-se à luz visível, esta afirmativa também é válida. No limite mais baixo de $400 \mathrm{~nm}$ ela se aproxima do intervalo do espectro da 
radiação ultravioleta, e no outro limite, de $700 \mathrm{~nm}$, ela se aproxima da infravermelha. Todas se irradiam pelo espaço com a mesma velocidade, que é de $300 \mathrm{mil} \mathrm{km} / \mathrm{s}$ ou $3 \times 10^{8} \mathrm{~m} / \mathrm{s}$. As diferenças estão no comprimento de onda e na freqüência da radiação, que fazem com que tenham diferentes características, como o poder de penetração dos raios x ou o aquecimento do infravermelho. As correspondências entre as unidades Angstron $(\AA)$ e nanômetros: $1 \AA=10^{-8} \mathrm{~cm}$ e $1 \mathrm{~nm}=10 \AA$.

AMPLIAÇÃO DO ESPECTRO VISIVEL EM $\AA$

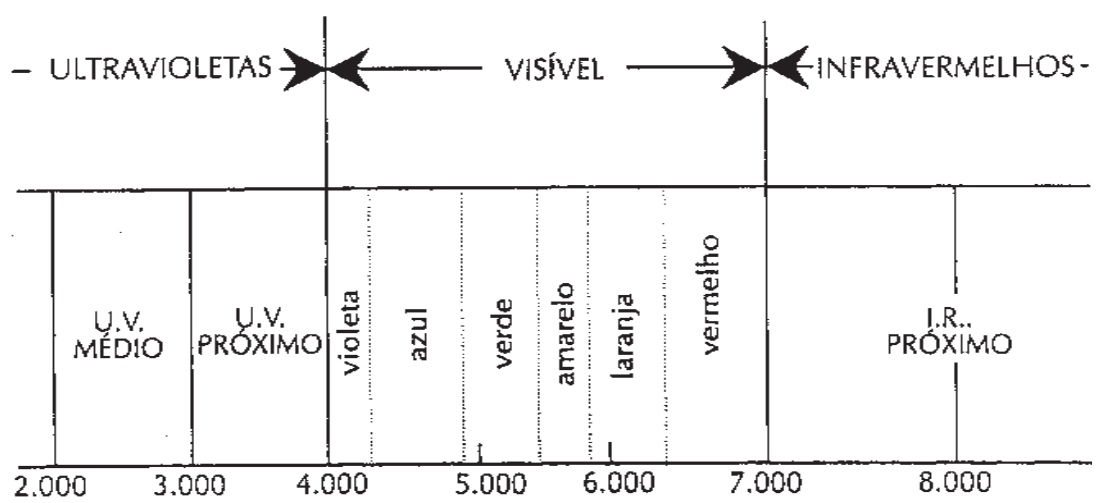

ESQUEMA DO ESPECTRO ELETROMAGNÉTICO EM UNIDADES $\AA$

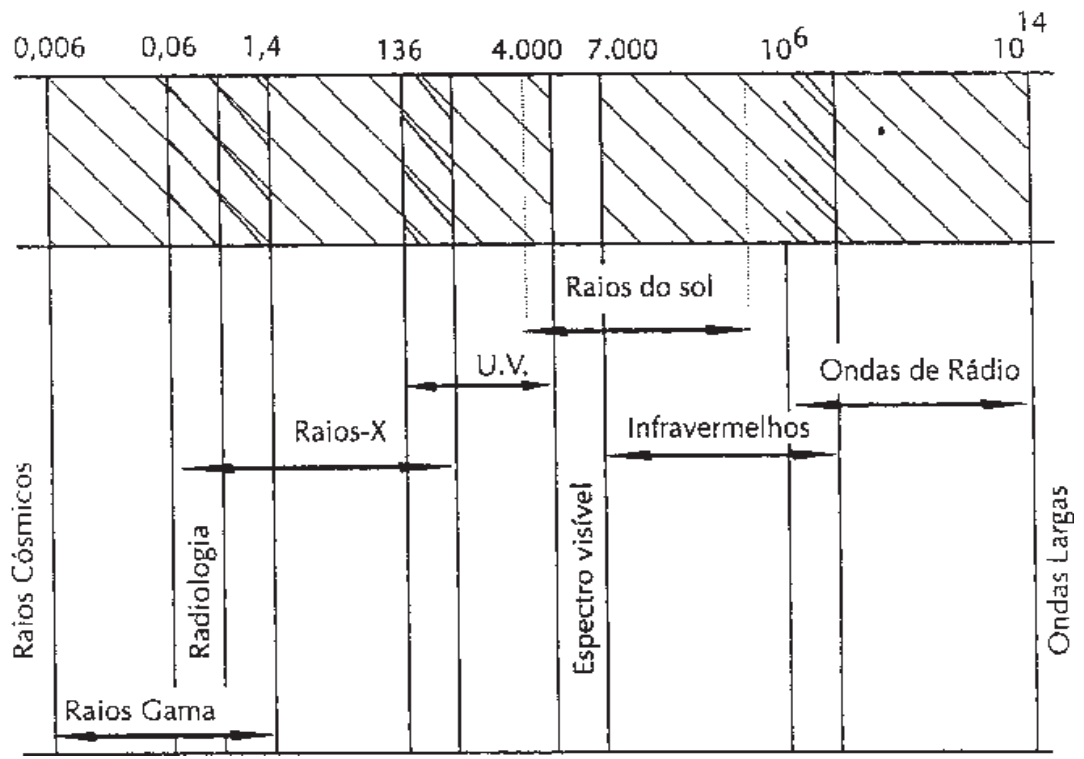


Uma fonte de radiação, como o Sol, pode emitir luz de um espectro variado. Por exemplo, decompondo-se a luz solar com um prisma é possível ver o espectro de cores, como as do arco-íris. Outras são invisíveis ao olho humano, mas detectáveis por instrumentos (FIGURA 2). $\bigcirc$ termo luz, por convenção, indica a região de ondas eletromagnéticas que se encontram entre as frequências de ondas de 400 a 770 nm (nanômetros), indo da cor ultravioleta à infravermelha, passando pela azul, verde, amarela e roxa. Esta é a região do espectro óptico ou luz visível, capaz de reproduzir a sensação visual. Estas cores (cor luz), quando somadas em quantidades iguais, definem o aspecto da luz branca ou luz do Sol.

Cada fonte de luz tem um espectro de radiação próprio, com comprimentos de onda distintos e com características e qualidades específicas. As radiações de infravermelho e de ultravioleta não são perceptíveis ao olho humano, mas podem ser detectadas por meio de película fotográfica ou equipamentos. Analisando as frequências de ondas do espectro, concluímos que partindo do ultravioleta para o infravermelho, o comprimento de onda vai do mais curto, que é a radiação mais energética, para o mais longo, menos energética. De onde concluímos que a radiação ultravioleta é a mais nociva dentro do espectro óptico, mas que não significa que é a única.

A influência da radiação de luz sobre os materiais de acervos museológicos e as conseqüências na degradação das coleções

A leitura do espectro da radiação eletromagnética indica como interpretar a ação das radiações, com seus respectivos comprimentos de onda, sejam elas visíveis ou não. As radiações ultravioleta são a forma de luz mais destrutiva e energética devido ao comprimento de onda mais curto e com maior frequência e mais energia. Atingindo um objeto com maior energia e num tempo mais curto, apresenta um grande potencial de dano. A luz ultravioleta, não sendo visível ao olho humano, não faz falta ao ambiente de uma sala de exposição, e tudo deve ser feito para eliminá-la ou para que atinja o nível mínimo aceitável.

$\bigcirc$ processo fotoquímico é gerado principalmente pela ação da ultavioleta, por ser uma fonte poderosa de energia. A ação fotoquímica é o processo no qual uma molécula sofre uma mudança na sua estrutura química, por exemplo, por meio de energia de ativação provocada pela absorção de um fóton de energia da luz. Os fótons emitidos chocam-se com as moléculas dos objetos expostos, e se a energia tiver potência suficiente, produzirá danos químicos irreversíveis. Como o próprio termo diz - "reação fotoquímica" é aquela que ocorre com a absorção de luz.

$\bigcirc$ processo de absorção de luz é melhor explicado nos termos da Teoria dos Orbitais Moleculares. Os elétrons dos átomos de uma molécula estão distribuídos nos orbitais atômicos em estados energéticos definidos. Cada orbital pode conter dois elétrons que ocupam uma região definida e uma energia também definida. Quando a molécula está no seu estado normal, esse sistema energético é o mais baixo possível e se mantém estável. Para que determinada molécula de uma matéria possa dar início a uma reação química com outras moléculas, ela necessita de uma certa quantidade de energia chamada energia de ativação. Os diferentes tipos de moléculas necessitam de diferentes energias de ativação. 


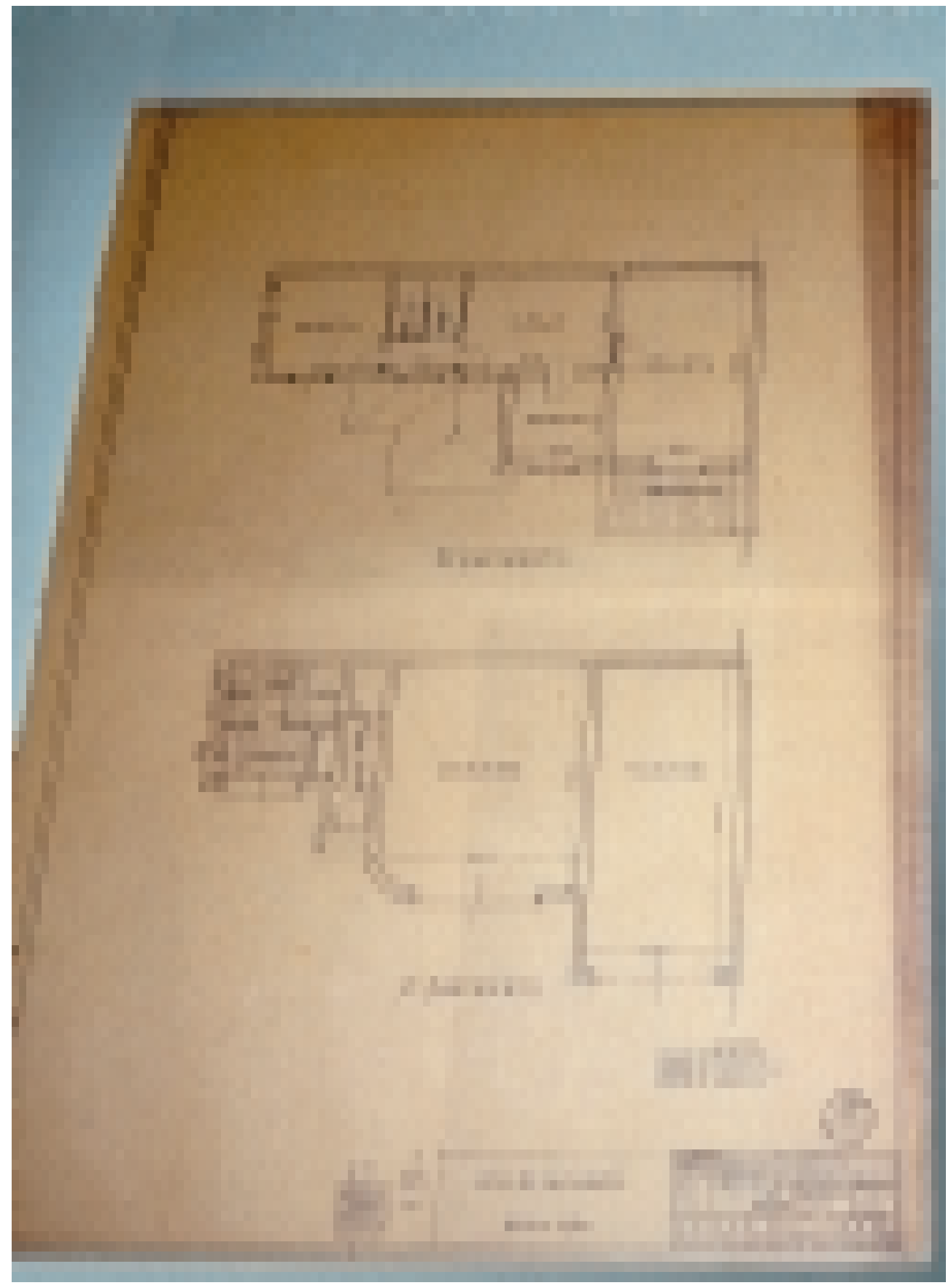

FIGURA 2 - Planta: é visível a ação da luz sobre a obra. O acondicionamento não cumpriu a função de proteger toda área da obra e as áreas que ficaram expostas tornaram-se escurecidas. Fotografia de Norma Cianflone Cassares. Acervo Biblioteca FAU/USP. 
Diz-se que agora a molécula está em estado excitado. A energia de excitação pode ser transferida de uma molécula para outra. Quando os elétrons excitados são transferidos para outras moléculas, ou quando outro elétron ocupa posição deixada pelo elétron excitado, ocorrem mudanças químicas. A molécula se torna um íon ou um radical, ou ambos, de natureza muito reativa. A molécula resultante pode se combinar com ela mesma, ou provocar reações com as moléculas próximas, iniciando uma reação em cadeia.

Portanto, quando uma molécula absorve fóton de energia de luz, natural ou artificial, seus elétrons são lançados para níveis mais altos de energia. Quando os elétrons voltam para seus níveis mais baixos de energia, eles liberam a mesma quantidade de energia que haviam absorvido. Esta liberação de energia pode romper as ligações e iniciar um processo de degradação. Conforme os comprimentos de onda ficam maiores na seqüência do espectro, elas tem menor energia, menor freqüência e menor capacidade de "excitar" as moléculas.

Uma das reações fotoquímicas primárias é a oxidação, muito freqüente e nociva para todos os materiais. Nela a molécula "excitada" transfere sua energia para um oxigênio que reage com outras moléculas, iniciando assim um complexo processo de degradação. A luz ultravioleta, no caso de obras em suporte-papel, não ataca diretamente a molécula da celulose. A absorção de luz não rompe diretamente as ligações químicas de cadeia de celulose. Porém as impurezas, partículas metálicas e certos aditivos existentes no papel irão absorver a energia emitida pela luz. Essa energia absorvida irá projetar seus elétrons para órbitas mais energéticas da eletrosfera dos seus átomos. Quando esta energia é liberada e incide na celulose, pode ocorrer o rompimento das ligações que favorece o processo oxidativo.

Os suportes como telas, tecidos, papel, como outras substâncias orgânicas, se oxidam sob a ação da radiação, e quando conjugados à ação da umidade se hidrolisam ou despolimerizam. $\bigcirc$ rompimento da cadeia polimérica se identifica pelo rompimento de fibras de papel, tecido, por exemplo. Outros materiais suscetíveis à ação da luz contidos numa pintura se danificam de formas diferenciadas. Os pigmentos e colorantes desbotam. Os vernizes tornam-se amarelecidos ou esbranquiçados, enquanto os aglutinantes das colas utilizadas na base de preparação podem se ressecar e contrair. A camada pictórica sobre esta base também é igualmente sensível à ação do infravermelho, que provoca a elevação de temperatura que, somada à umidade relativa acabam por produzir dilatação e contração desses materiais, surgindo assim os craquelados.

Os danos causados pelos efeitos da radiação são tão mais graves quando: o tempo de exposição for mais longo, a intensidade da radiação de luz incidente no objeto for maior, quando a luz contém mais radiações azuis, violeta e ultravioleta, e quando a temperatura e a umidade relativa são mais altas. A elevação dos níveis de iluminação numa exposição para pôr em maior evidência - valor de uma obra, ou pela justificativa da estética da exposição, é totalmente equivocada e tem conseqüências nefastas para a conservação das pinturas.

A identificação de danos pela ação da luz pode ser feita de forma prática através de observação da aparência na celulose de papel, tintas, couros, têxteis utilizados em revestimentos das encadernações, jornais etc. (FIGURAS 3-9). Devemos lembrar que a ação das radiações, quando associadas às condições ambientais inadequadas, como temperatura e umidade relativa em índices elevados, assim como a presença de partículas de gases poluentes do ar, entre outras, potencializam as reações de degradação instaladas no material. 


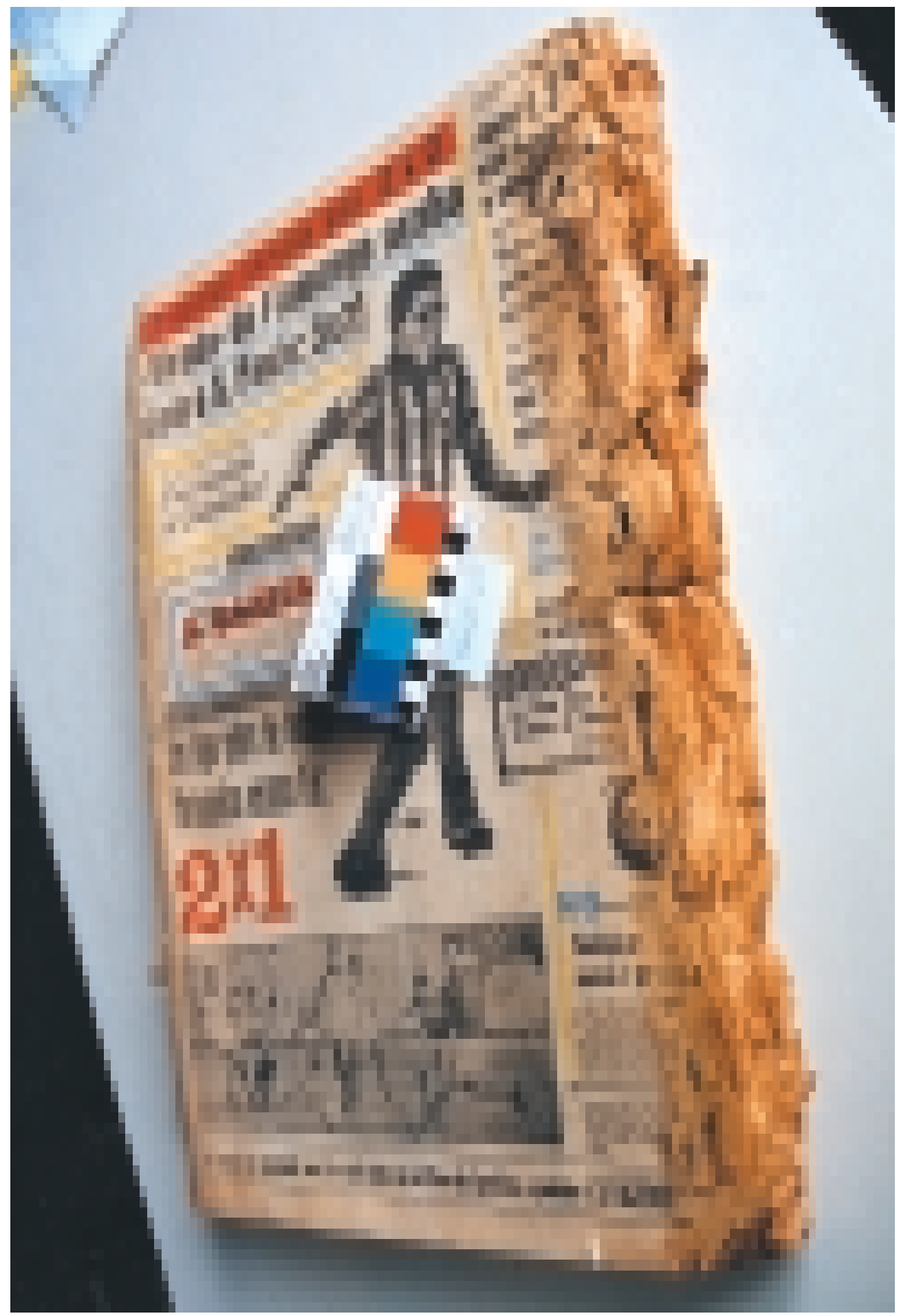

FIGURA 3 - O mesmo processo químico foi desencadeado no exemplar do jornal, com o agravante da existência de substâncias químicas residuais do processo de fabricação do papel. Fotografia de Norma Cianflone Cassares. Acervo particular. 


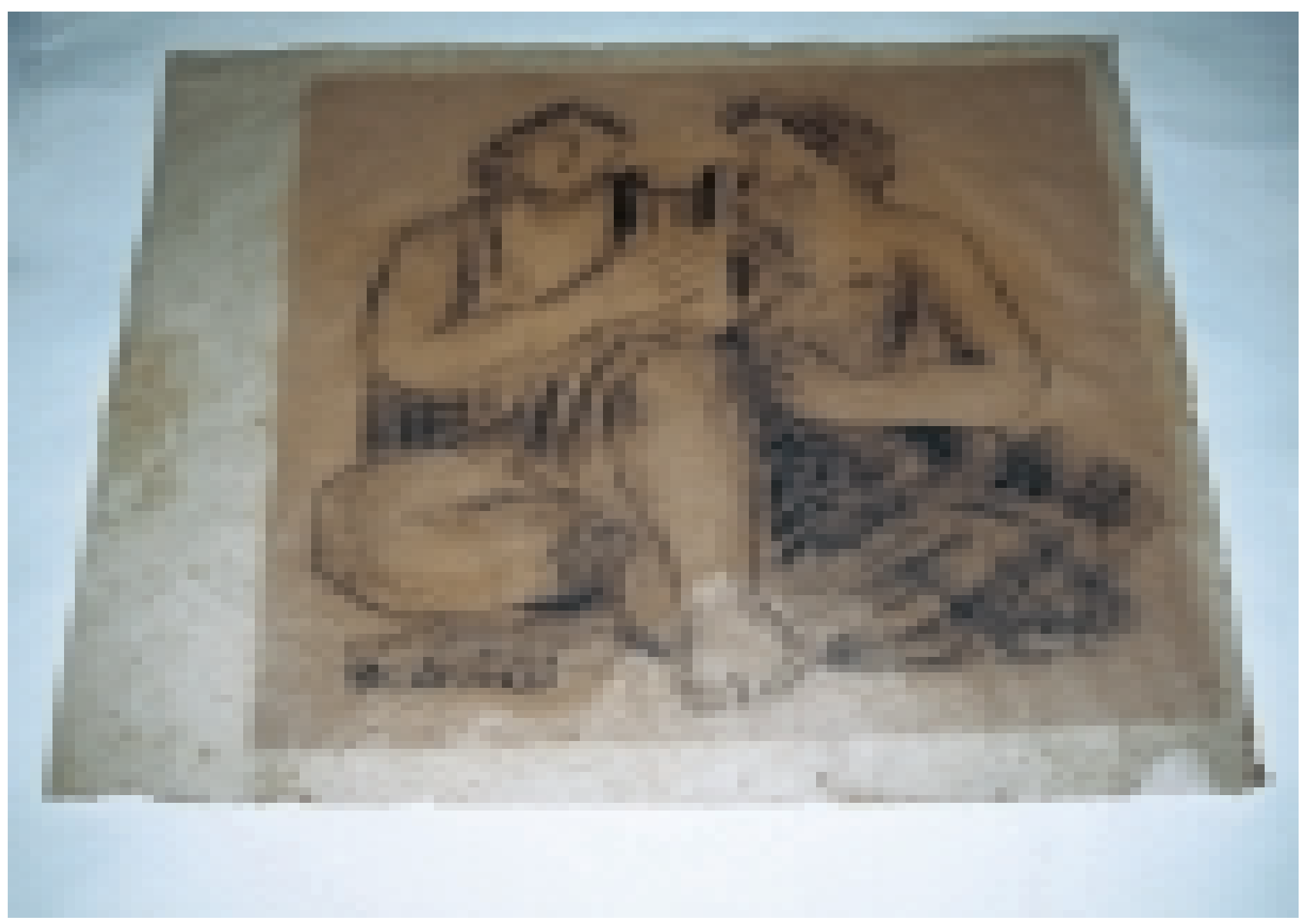

FIGURA 4 - Obra sofreu danos devido ao longo tempo de exposição e iluminação em níveis elevados. O papel escureceu e as laterais estão mais claras porque estavam protegidas da luz. Fotografia de Norma Cianflone Cassares. Acervo particular. 


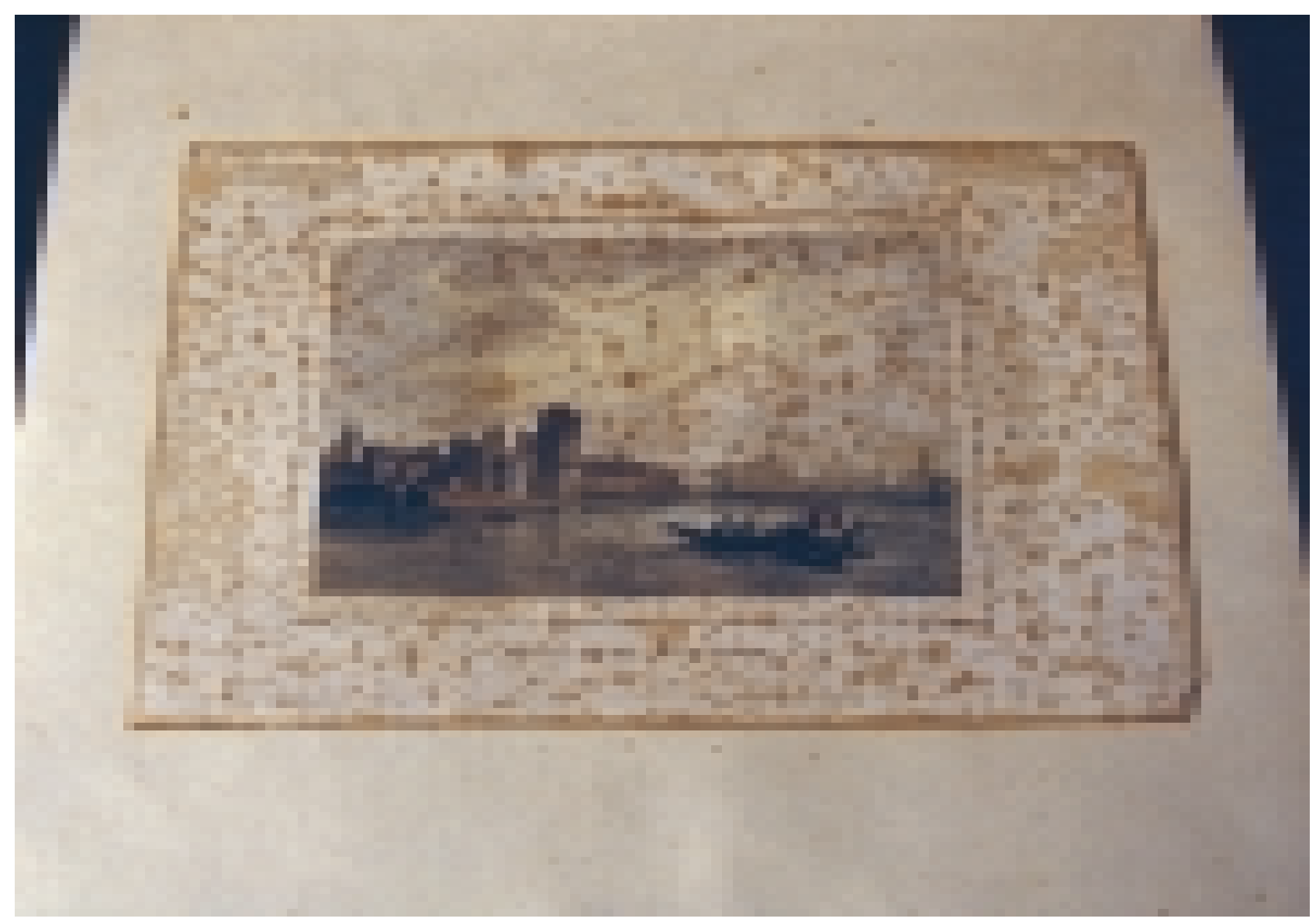

FIGURA 5 - Um exemplo de danos da radiação combinados com as impurezas de fabricação, entre elas partículas de metal (Fe) e o resultado é a degradação por oxidação e acidez. Fotografia de Norma Cianflone Cassares. Acervo particular. 


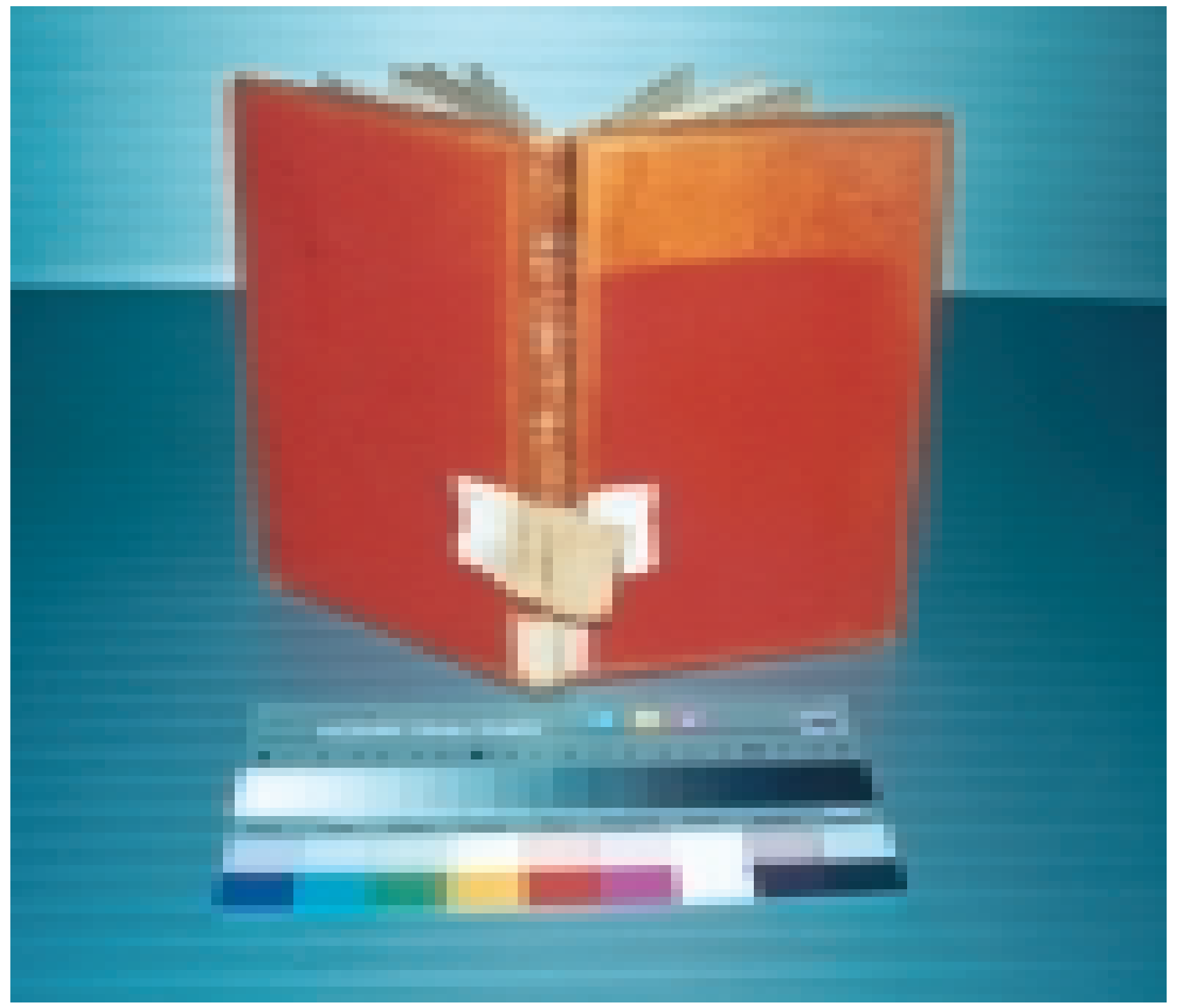

FIGURA 6 - A luz causou desbotamento na cor do couro, na área exposta à radiação de luz. Fotografia de Norma Cianflone Cassares. Acervo particular. 


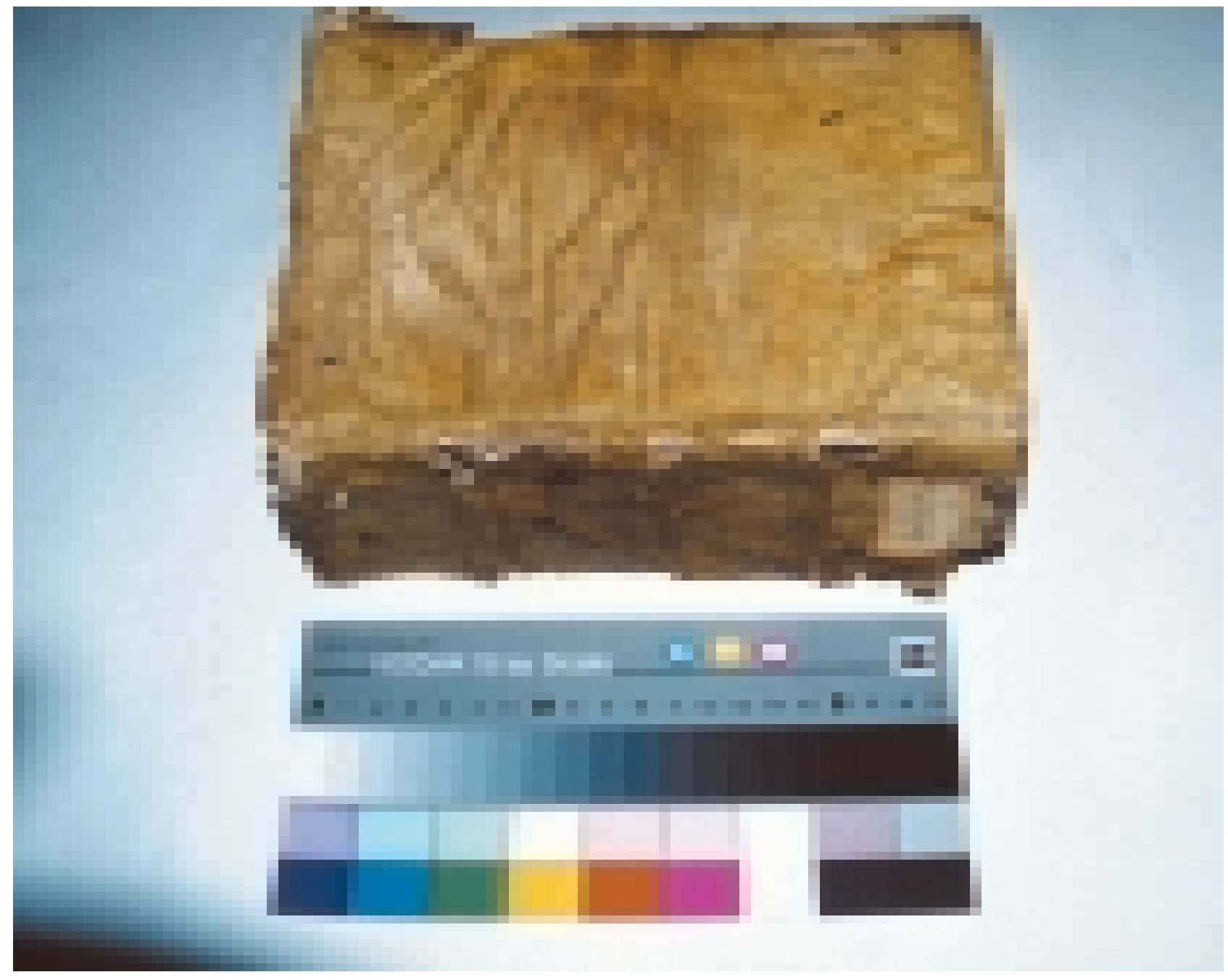

FIGURA 7 - Danos causados pela ultravioleta e infravermelha no pergaminho utilizado na encadernação: ressecamento, distorção e fragilização. 


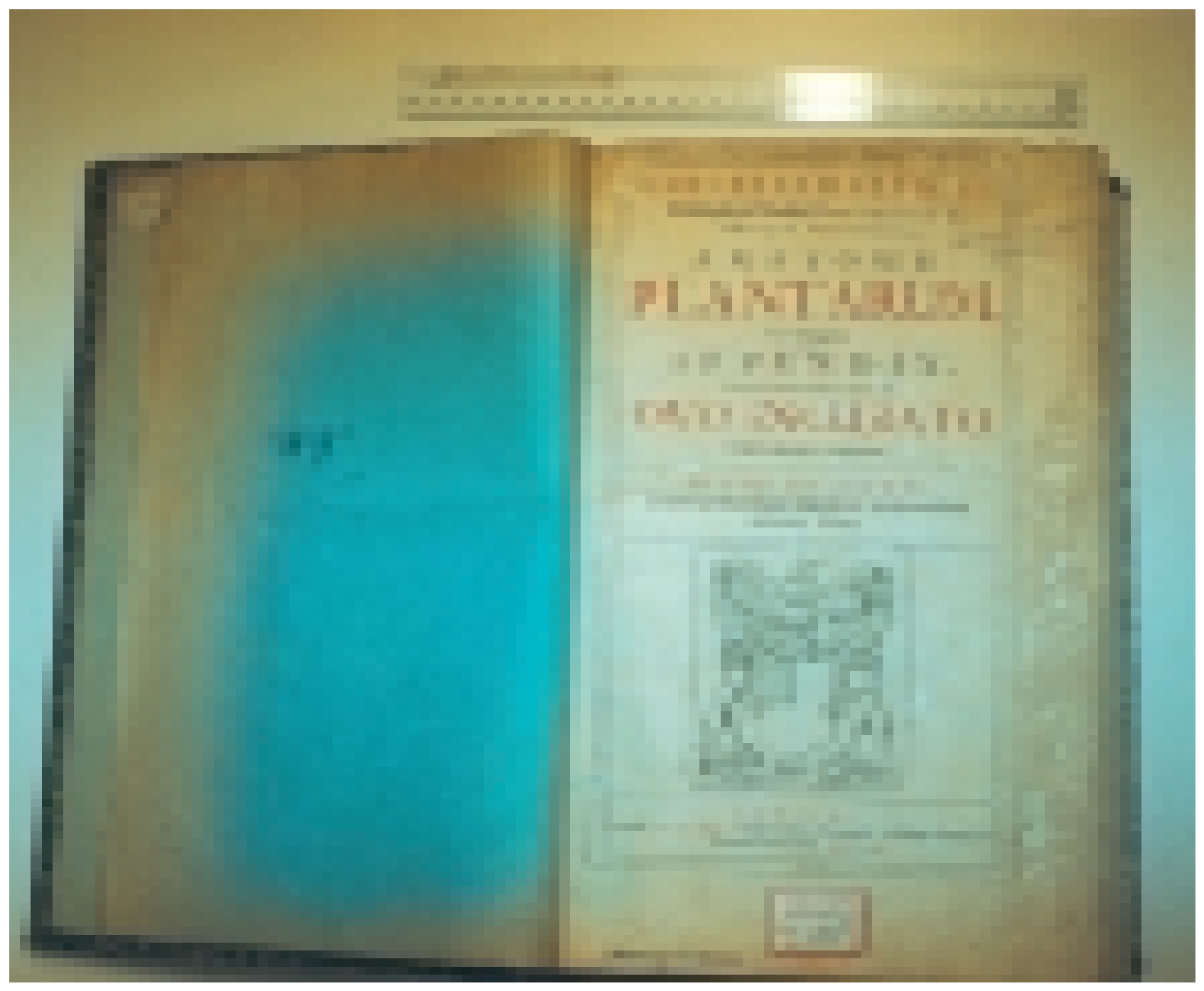

FIGURA 8 - Desbotamento do papel pela ação da luz ultravioleta nos cortes da guarda. Fotografia DE Norma Cianflone Cassares. Acervo Instituto de Biociências da USP. 


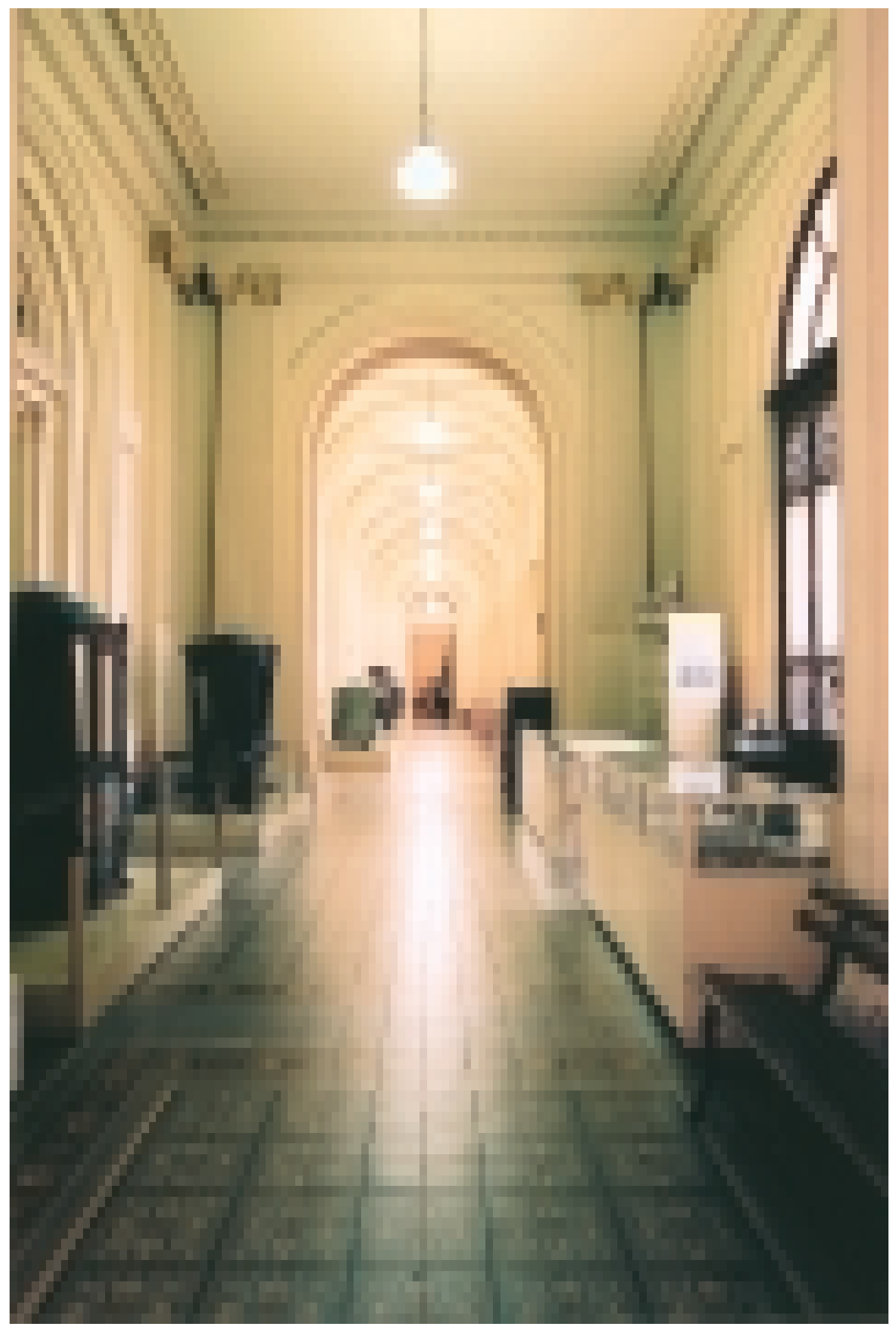

FIGURA 9 - Galeria anteriormente iluminada com lâmpada mista (Azulada) criando tons esverdeados, alterando a cor das paredes. Fotografia de José Rosael, edifício Museu Paulista. 
Princípio da Reciprocidade e as unidades de medidas da intensidade da luz

A intensidade da iluminação de um ambiente se dá através da unidade de medida chamada lux. É definida como a iluminância que recebe uma superfície de $1 \mathrm{~m}^{2}$ sobre a qual incide um fluxo luminoso de um lúmen. $\bigcirc$ Princípio da Reciprocidade considera o tempo de exposição dos objetos à radiação-luz e a intensidade da iluminação. Existe uma concordância entre os especialistas da área em que a meta de 200.000 lux/h por ano é aceitável para materiais sensíveis à luz. As opções para a exposição podem variar, por exemplo, em 50 dias com 100 lux por dia ou 50 lux por 100 dias. Enfim, o somatório de lux por ano não deve ultrapassar os índices recomendados. Portanto, devemos ressaltar que é de suma importância o planejamento de tempo de exposição de um objeto, e não só pela aplicação do nível de intensidade de luz recomendada em tabelas consideradas adequadas.

Materiais em processo de degradação têm que ser avaliados individualmente, se devem ou não ser expostos, considerando o conjunto das condições ambientais que se somam às ações da luz. Os processos de danos não ocorrem de forma isolada, mas sempre causados pelas complexas condições ambientais. Numa montagem de exposição devemos ter em consideração um planejamento de incidência de iluminação nas obras, sem esquecer a segurança e o conforto visual do visitante.

Além deste estudo dos processos de danos, há ainda outros parâmetros a ser considerados. Quanto à qualidadedas lâmpadas atualmente oferecidas no mercado, tanto os fabricantes como os usuários estão preocupados com o consumo e custo de energia. Então, o uso racional e econômico de energia passou a ser mais uma referência na escolha das lâmpadas utilizadas num projeto de iluminação.

Com o uso indiscriminado de iluminação artificial com níveis exagerados de irradiação nos locais de exposição, os danos estão se tornando ainda mais intensos e irreversíveis aos elementos componentes das obras expostas.

\section{Algumas considerações acrescentadas ao tema da Luz}

Temperatura de cor - é a grandeza que expressa a aparência de cor da luz e sua unidade é Kelvin (K). Quanto mais alta a temperatura de cor, mais branca é a cor da luz. A luz quente é a que tem aparência amarelada e temperatura de cor baixa: 3.000 K. A luz fria, ao contrário, tem aparência azul-violeta, com temperatura de cor elevada: $6.000 \mathrm{~K}$ ou mais. A luz branca natural é a emitida pelo Sol em céu aberto ao meio-dia, e tem a temperatura de cor de 5.800. A âmpada mista em tom azulado, como mostra a Figura 9, cria tons esverdeados no ambiente em reação com as cores das paredes. Na Figura 10, utilizando-se as lâmpadas fluorescentes compactas amareladas, produz-se um ambiente mais agradável que se harmoniza com as cores das paredes. Embora seja um conceito subjetivo, a luz amarelada, para a maioria das pessoas, é considerada mais agradável aos nossos olhos. 


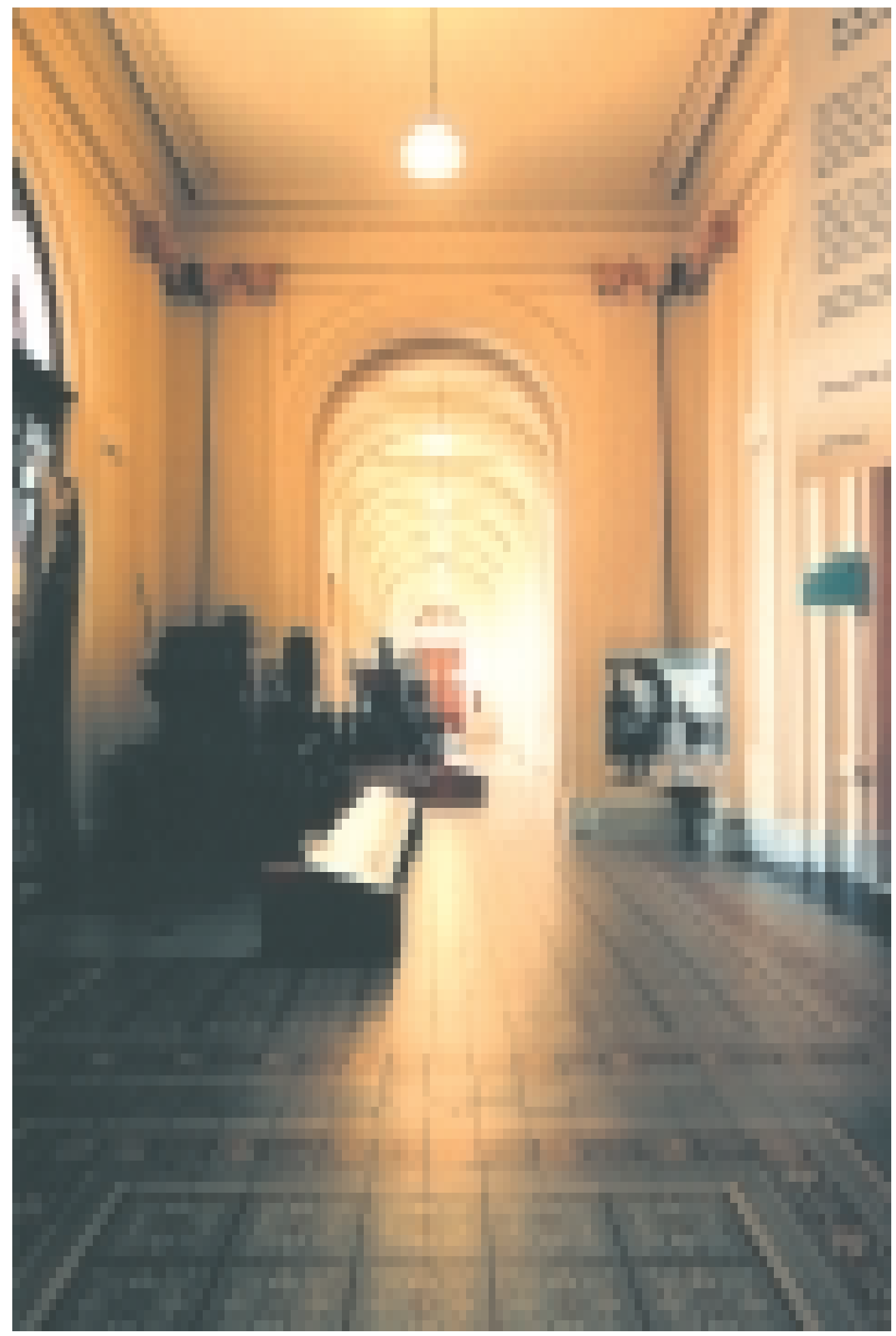

FIGURA 10 - Galeria iluminada com lâmpada fluorescente compacta (amarelada) mantendo a cor das paredes. Fotografia de José Rosael, edifício Museu Paulista. 
Índice de Reprodução de Cor: Ra ou IRC - é a medida de correspondência entre a cor real de um objeto ou superfície e sua aparência diante da fonte de luz. A luz artificial, como regra, deve permitir ao olho humano perceber as cores corretamente ou o mais próximo possível da luz natural. Lâmpadas com Ra de 100\% apresentam as cores com total fidelidade e precisão. Quanto mais baixo o índice, mais deficiente é a reprodução de cores. A lâmpada incandescente tem $100 \%$, a fluorescente compacta 89 , e a mista 50 .

Recomendações importantes para amenizar ou mesmo excluir a incidência de radiação em acervos

A instituição deve implementar uma política de controle ambiental, em que esteja incluído o controle de incidência de radiação luminosa tanto nos acervos, como nas reservas técnicas e exposições; buscar sempre especial istas que orientem quanto ao uso de tipos mais adequados de lâmpadas para a conservação do acervo; manter na política de conservação uma metodologia de controle e monitoramento das áreas onde incide a luz natural, e também a artificial e buscar a instalação de filtros adequados que sirvam de barreira para as radiações em áreas onde haja a incidência comprovada principalmente de ultravioleta e infravermelho.

\section{REFERÊNCIAS}

CUTTLE, Christopher. Damage to Museum Objects Due to Light Exposure. International Journal of Lightning Research and Technology, v. 28, n. 1, p. 1,2,12 e 13.

MICHALSKI, Stefan. Time's Effects on Paintings. In: CONFERENCE SHARED RESPONSIBILITY: A SEMINAR FOR CURATORS AND CONSERVATORS, 1990, Ottawa. Shared Responsability. Ottawa: National Gallery of Canada. 1990. p. 39-53, reprinted.

MICHALSKI Stefan .Towards Specific Lighting Guidelines. Preprints of THE 9TH TRIENNIAL MEETING, DRESDEN , GERMANY ( LOSANGELES ICOM COMMITTEE FOR CONSERVATION 1990 ) : vol II Working Group \#17 Lighting and Climate Control ,p. 583-588. Reprinted by permission of the author.

RESNICH, Robert. Física. [s.1.]: Ed. Livros Técnicos e Científicos Editora, 1974.v. 1, p. 154.

WILLIAMS, John E. ; METCALFE , H. Clark;TRINKLEIN, Frederic E.; LEFLER, Ralph W. ; MELLO, L.J. Silva. Física moderna. Rio de Janeiro: Ed. Renes, 1970. v. 2, p. 259-304.

Artigo apresentado em 10/2003. Aprovado em 11/2003. 
Influência da radiação de luz sobre acervos museológicos

\section{Norma Ciaflone Cassares, Yara Lígia Mello Moreira}

O texto analisa a ação e os efeitos da radiação de luz sobre acervo museológico. Considera-se a luz como fator de dano produzindo alterações físicas e químicas sobre a estrutura molecular dos materiais dos objetos, que ocorrem sempre em conjunto com as condições ambientais e não de forma isolada. Aponta critérios técnicos, referências, relativos aos níveis de iluminação e ao tempo de exposição dos objetos.

PALAVRAS-CHAVE: Conservação. Luz. Museus.Acervos.

Anais do Museu Paulista. São Paulo. N. Sér. v. 8/9. p.177-192 (2000-2001). Editado em 2003

Influence of the light radiation on the museum's collections

\section{Norma Ciaflone Cassares, Yara Lígia Mello Moreira}

The text analyses the actions and effects of light on the museum's collections. Light is considered of harmful effects leading to physical and chemical changes on the molecular structure of the materials of the objects, which always happen together with the environmental conditions rather than alone. It points out towards technical criteria, references, related to the levels of light and the exposure time of the objects.

KEYWORDS: Conservation. Light. Museums. Collections.

Anais do Museu Paulista. São Paulo. N. Sér. v. 8/9. p.177-192 (2000-2001). Editado em 2003.

Conservação de coleções em ambientes tropicais: coletando e comunicando dados do Museu Paulista/USP, Brasil (1997-2000)

Teresa Cristina Toledo de Paula

As atividades de monitoramento e controle ambiental nas regiões temperadas originaram os parâmetros e práticas hoje estabelecidos mundialmente para a conservação de acervos; tais parâmetros e práticas, entretanto, podem não ser adequados à conservação de acervos em regiões tropicais. Este trabalho apresenta uma pesquisa sobre as condiç̃̃es ambientais em museu de região tropical, o Museu Paulista da Universidade de São Paulo. Trinta e três salas, halls e corredores nos quatro pavimentos do Museu Paulista têm sido monitorados por termo-higrógrafos desde 1997. Grandes variações na UR (30-98\%) e temperatura (1 2-35 graus C) foram registradas. efeito nocivo sobre as coleções, esperável em situações climáticas tão inconstantes, não foi encontrado onde há ventilação apropriada. O monitoramento possibilitou, também, a identificação de áreas de alto risco, onde ações localizadas podem ser introduzidas de forma econômica. Desenvolver um modo efetivo de comunicar essas informações ambientais à equipe do museu mostrou-se vital à implementação de medidas sustentáveis de monitoramento e controle climáticos. PALAVRAS-CHAVE: Clima em Museu. Clima Tropical. Clima Brasileiro. Museus Brasileiros. Monitoramento Ambiental. Anais do Museu Paulista. São Paulo. N. Sér. v. 8/9. p.193-278 (2000-2001). Editado em 2003.

Caring for Collections in Tropical Environments: Collecting and Communicating Data at Museu Paulista/USP, Brasil (1997-2000)

Teresa Cristina Toledo de Paula

The monitoring and environment control activities in the temperate regions have originated the parameters and the actions now established, world widely, for the conservation of the collections; such parameters and the actions, nevertheless, may not be adequate for the conservation of the collections in tropical regions. This work presents a research about the environmental conditions in a museum in a tropical region, the Museum of the University of São Paulo Museu Paulista da Universidade de São Paulo). Thirty-three rooms, halls and corridors in the four of the museums floors have been monitored with thermo hygrographs since 1997. Huge variations in the UR (30-98\%) and temperature (12-35 degrees C) have been registered. The harmful effect on the collections, expected in so changeable climatic situations, has not been found where there is proper ventilation. The monitoring has also enabled the identification of the high-risk areas, where local actions can be introduced in an economical way. Developing an effective way of passing ahead this environment information to the museum's staff has been proved vital for the implementation of sustainable measures of monitoring and climatic control.

KEYWORDS: Climate in a Museum.Tropical Climate. Brazilian Climate. Brazilian Museums. Environmental Monitoring.

Anais do Museu Paulista. São Paulo. N. Sér. v. 8/9. p.193-278 (2000-2001). Editado em 2003. 